\title{
Endogenous Secretory Receptor for Advanced Glycation End Products and Chronic Kidney Disease in the Elderly Population
}

\author{
Mansi Dalal ${ }^{\mathrm{a}}$ Richard D. Semba ${ }^{\mathrm{a}}$ Kai Sun ${ }^{\mathrm{a}}$ Candace Crasto $^{\mathrm{a}}$ Ravi Varadhan $^{\mathrm{b}}$ \\ Stefania Bandinellic Jeffrey C. Fink ${ }^{d}$ Jack M. Guralnik ${ }^{\mathrm{e}}$ Luigi Ferrucci $^{f}$ \\ Departments of a Ophthalmology and ${ }^{b}$ Medicine, Johns Hopkins University School of Medicine, Baltimore, Md., USA; \\ ${ }^{\mathrm{C}}$ Azienda Sanitaria Firenze, Florence, Italy; ${ }^{\mathrm{d}}$ Division of Nephrology, Department of Medicine, University of \\ Maryland School of Medicine, Baltimore, Md., ' Laboratory of Epidemiology, Demography, and Biometry, National \\ Institute on Aging, Bethesda, Md., and fLongitudinal Studies Section, Clinical Research Branch, National Institute on \\ Aging, Baltimore, Md., USA
}

\section{Key Words}

Advanced glycation end products - Aging - Chronic kidney disease $\cdot$ Endogenous secretory receptor for advanced glycation end products

\begin{abstract}
Background/Aims: The relationship of circulating endogenous secretory receptor for advanced glycation end products (esRAGE) and chronic kidney disease (CKD) has not been well characterized. The aim of the study was to determine whether plasma esRAGE is associated with CKD and is predictive of developing CKD in older adults. Methods: The relationship between plasma esRAGE and CKD (more than stage 3 of the National Kidney Foundation classification; estimated glomerular filtration rate $<60 \mathrm{ml} / \mathrm{min} / 1.73 \mathrm{~m}^{2}$ ) and CKD over 6 years of follow-up was examined in a cross-sectional and prospective study design in 1,016 men and women, $\geq 65$ years, in the InCHIANTI study, a population-based cohort study of aging in Tuscany, Italy. Results: At enrollment, 158 (15.5\%) had CKD. Mean (SD) plasma esRAGE was $0.45(0.24) \mathrm{ng} / \mathrm{ml}$. Plasma esRAGE $(\mathrm{ng} / \mathrm{ml})$ was associated with CKD (odds ratio per 1 SD $=1.30 ; 95 \%$ Cl 1.1-1.6; $p<0.005$ ) in a multivariable logistic regression model, adjusting for po-
\end{abstract}

tential confounders. Plasma esRAGE was an independent predictor of incident CKD over 6 years of follow-up (hazard ratio per $1 \mathrm{SD}=1.37 ; 95 \% \mathrm{Cl} 1.1-1.7 ; \mathrm{p}<0.008$ ) in a multivariable Cox proportional hazards model, adjusting for potential confounders. Conclusions: Elevated plasma esRAGE is independently associated with CKD and is an independent predictor of incident CKD in older community-dwelling adults.

Copyright $\odot 2011$ S. Karger AG, Basel

\section{Introduction}

Chronic kidney disease (CKD) disproportionately burdens the aging population. Age, race, dyslipidemia, diabetes, hypertension and lifestyle factors such as tobacco use and inactivity are known risk factors for the development of CKD [1]. However, these risk factors account for only a small fraction in the older population. Thus, it is important to identify novel risk factors related to underlying pathophysiology that could be targeted by interventions.

Oxidative stress and inflammation appear to play key roles in the progression of kidney disease in older persons [2]. Advanced glycation end products (AGEs) are bioactive molecules formed by the non-enzymatic glycation of

\section{KARGER}

두 2011 S. Karger AG, Basel

Fax +41613061234 E-Mail karger@karger.ch www.karger.com www.karger.com/ajn
Dr. Richard Semba

M015, Smith Building, 400 N. Broadway

Baltimore, MD 21287 (USA)

Tel. +1 4109553572

E-Mail rdsemba@jhmi.edu 
proteins and other molecules. AGEs have been implicated in the pathogenesis of CKD, diabetes, and atherosclerosis [3-5]. AGEs increase oxidative stress by both generating reactive oxygen species and by upregulating inflammation through the receptor for AGE (RAGE) and the NF$\kappa \mathrm{B}$ pathway [6].

RAGE is a cell-surface multiligand member of the immunoglobulin superfamily and its activation induces cellular dysfunction and tissue-destructive responses in many chronic disease states including diabetes [7]. In addition to the full-length cell surface RAGE (sRAGE), circulating isoforms of RAGE include endogenous secretory RAGE (esRAGE), a splice variant of RAGE secreted into blood lacking the transmembrane and cytoplasmic portion of the receptor and truncated forms cleaved from the sRAGE $[8,9]$. The exact role of esRAGE has not been well characterized. It has been hypothesized that esRAGE neutralizes AGEs in the circulation by binding with AGEs and inhibiting the AGE-RAGE axis [8]. Thus, esRAGE could play a role as a decoy receptor and protect against the harmful effects caused by activation of the AGERAGE axis.

Several studies have linked elevated levels of esRAGE to diabetic complications, decreased renal function, and end-stage renal disease (ESRD) [10-12]. In contrast, other studies have shown that low esRAGE levels are associated with atherosclerosis and the metabolic syndrome and are predictive of cardiovascular death in patients with ESRD [13]. Our previous studies show that carboxymethyl-lysine (CML), a major circulating AGE, as well as sRAGE and esRAGE are inversely associated with renal function in moderately to severely disabled older women living in the community [14]. The specific aim of the present study was to determine whether elevated plasma esRAGE concentrations are associated with CKD and predict incident CKD, independent of CML. To address this aim, we examined the relationship between plasma esRAGE and prevalent and incident CKD in older men and women living in the community.

\section{Subject and Methods}

\section{Participants}

The participants were men and women, 65 and older, who participated in the Invecchiare inChianti, 'Aging in the Chianti Area' (InCHIANTI) study, a population-based study conducted in two small towns, Greve in Chianti and Bagno a Ripoli in Tuscany, Italy. The rationale, design, and data collection are described elsewhere and the main outcome of this longitudinal study is mobility disability [14]. Participants were enrolled after written, in- formed consent. The study protocol complied with the Declaration of Helsinki and was approved by the Italian National Institute of Research and Care on Aging Ethical Committee. The plan for secondary data analysis was approved by the Institutional Review Board of the Johns Hopkins University School of Medicine.

The demographic information and information on smoking and medication use were collected using standardized questionnaires. Smoking history was determined from self-report and dichotomized in the analysis as 'current smoking' versus 'ever smoked' and 'never smoked.' Education was recorded as years of school. All participants were examined by a trained geriatrician and diseases were ascertained according to standard, pre-established criteria and algorithms based upon those used in the Women's Health and Aging Study for coronary heart disease, chronic heart failure, stroke, and cancer [14]. Body mass index (BMI) was calculated as weight $/$ height ${ }^{2}\left(\mathrm{~kg} / \mathrm{m}^{2}\right)$. The Mini Mental State Examination (MMSE) was administered at enrollment [14]. CKD was defined as estimated glomerular filtration rate of $<60 \mathrm{ml} /$ $\mathrm{min} / 1.73 \mathrm{~m}^{2}$ using the four-variable Modification of Diet in Renal Disease Study (MDRD) equation of Levey et al. [15]. Participants were evaluated again for a 3-year follow-up visit from 2001 to 2003 $(\mathrm{n}=926)$ and 6-year follow-up visit from 2004 to $2006(\mathrm{n}=858)$.

\section{Laboratory Analyses}

Blood samples were collected in the morning after a 12-hour fast. Aliquots of plasma were immediately obtained and stored at $-80^{\circ} \mathrm{C}$. Plasma esRAGE was measured at enrollment using a sandwich ELISA that employs a polyclonal antibody raised against the unique C-terminal 16-amino-acid peptide only present on esRAGE and not on any other sRAGE (B-Bridge International, Inc., Mountain View, Calif., USA) [14]. Plasma CML, a dominant AGE in the circulation, was measured at enrollment using a competitive ELISA according to the manufacturer's protocol (AGE-CML ELISA, MicroCoat Biotechnologie GmbH, Bernried am Starnberger See, Germany) [14]. This assay has been validated [16], is specific, and shows no cross-reactivity with other compounds [16]. The intra- and inter-assay coefficients of variation (CVs) for plasma esRAGE were 4 and 9\%, while for plasma CML they were 3 and $11 \%$, respectively. High sensitivity C-reactive protein (CRP) was measured using ELISA and a colorimetric competitive immunoassay (Calbiochem, San Diego, Calif., USA). Inter- and intra-assay CV were $<5 \%$. Serum interleukin-6 (IL-6) was measured using ELISA (BioSource, Inc., Camarillo, Calif., USA). Inter- and intra-assay CVs were $<7 \%$.

\section{Statistical Analysis}

Variables are reported as medians (25th, 75th percentiles) or as percentages. Characteristics of subjects according to CKD diagnosis were compared using Wilcoxon rank sum tests for continuous variables and $\chi^{2}$ tests for categorical variables. Age and BMI were analyzed as categorical variables because the relationship between age, BMI, and renal function was non-linear. Correlation between esRAGE and CML was determined using Spearman correlation. Uni- and multivariable logistic regression models were used to examine the relationship between plasma esRAGE and CKD at enrollment. Variables that were significantly associated with CKD in the univariable analyses were entered into the multivariable analyses. Cox proportional hazards models were used to examine the relationship between plasma esRAGE at enrollment and incident CKD over 6 years of follow-up. An interaction variable between 
Table 1. Demographics and health characteristics of men and women, with and without CKD, at enrollment in the InCHIANTI study $(\mathrm{n}=1,016)$

\begin{tabular}{|c|c|c|c|c|c|c|}
\hline \multirow[t]{2}{*}{ Characteristic $^{\mathrm{a}}$} & & \multicolumn{2}{|c|}{$\mathrm{CKD}(\mathrm{n}=158)$} & \multicolumn{2}{|c|}{ No CKD $(\mathrm{n}=858)$} & \multirow[t]{2}{*}{$\mathrm{p}$} \\
\hline & & $\mathrm{n}$ & $\begin{array}{l}\text { \% or median } \\
\text { (25th, } 75 \text { th percentile) }\end{array}$ & $\mathrm{n}$ & $\begin{array}{l}\% \text { or median } \\
\text { (25th, } 75 \text { th percentile) }\end{array}$ & \\
\hline \multirow[t]{6}{*}{ Age, years } & $65-69$ & 19 & 12.0 & 265 & 30.9 & \multirow[t]{6}{*}{$<0.0001$} \\
\hline & $70-74$ & 29 & 18.3 & 241 & 28.1 & \\
\hline & $75-79$ & 33 & 20.9 & 176 & 20.5 & \\
\hline & $80-84$ & 34 & 21.5 & 81 & 9.4 & \\
\hline & $85-89$ & 26 & 16.5 & 60 & 7.0 & \\
\hline & $\geq 90$ & 17 & 10.8 & 35 & 4.1 & \\
\hline \multirow[t]{2}{*}{ Gender } & Female & 120 & 75.9 & 458 & 53.4 & \multirow[t]{2}{*}{$<0.0001$} \\
\hline & Male & 38 & 24.1 & 400 & 46.6 & \\
\hline Education, years & & 157 & $5.0(3.0,5.0)$ & 858 & $5.0(4.0,6.0)$ & 0.0029 \\
\hline \multirow[t]{3}{*}{ Smoking status } & Never & 110 & 69.6 & 496 & 57.8 & \multirow[t]{3}{*}{0.007} \\
\hline & Former & 37 & 23.4 & 236 & 27.5 & \\
\hline & Current & 11 & 6.7 & 126 & 14.7 & \\
\hline \multicolumn{2}{|l|}{ BMI } & 141 & $27.2(24.1,30.4)$ & 808 & $27.2(24.7,29.8)$ & 0.98 \\
\hline \multicolumn{2}{|c|}{ Serum creatinine, $\mathrm{mg} / \mathrm{dl}$} & 158 & $1.1(1.0,1.3)$ & 858 & $0.87(0.8,1.0)$ & $<0.0001$ \\
\hline \multicolumn{2}{|c|}{ Estimated glomerular filtration rate, $\mathrm{ml} / \mathrm{min} / 1.73 \mathrm{~m}^{2}$} & 158 & $53.8(48.5,57.0)$ & 858 & $76.4(69.5,87.2)$ & $<0.0001$ \\
\hline \multicolumn{2}{|c|}{ Plasma esRAGE ${ }^{\mathrm{b}}, \mathrm{ng} / \mathrm{ml}$} & 158 & $0.53(0.35,0.67)$ & 858 & $0.44(0.29,0.53)$ & $<0.0001$ \\
\hline \multicolumn{2}{|c|}{ Plasma CML, ng/ml } & 152 & $389(322,473)$ & 837 & $343(285,412)$ & $<0.0001$ \\
\hline \multicolumn{2}{|c|}{$\log \mathrm{CRP}, \mu \mathrm{g} / \mathrm{ml}$} & 158 & $1.11(0.44,1.76)$ & 858 & $1.02(0.26,1.76)$ & 0.11 \\
\hline \multicolumn{2}{|l|}{$\log \mathrm{IL}-6, \mathrm{~g} / \mathrm{ml}$} & 157 & $1.23(0.84,1.62)$ & 853 & $1.06(0.69,1.37)$ & 0.002 \\
\hline \multicolumn{2}{|l|}{ MMSE score $<24$} & 65 & 27.5 & 236 & 41.1 & 0.0006 \\
\hline \multicolumn{2}{|l|}{ Hypertension } & 85 & 53.8 & 400 & 46.6 & 0.10 \\
\hline \multicolumn{2}{|c|}{ Angina } & 8 & 5.1 & 36 & 4.2 & 0.62 \\
\hline \multicolumn{2}{|c|}{ Peripheral artery disease } & 12 & 7.6 & 49 & 5.7 & 0.36 \\
\hline \multicolumn{2}{|c|}{ Congestive heart failure } & 21 & 13.3 & 34 & 4.0 & $<0.0001$ \\
\hline \multicolumn{2}{|c|}{ Stroke } & 15 & 9.5 & 39 & 4.6 & 0.01 \\
\hline \multicolumn{2}{|l|}{ Diabetes mellitus } & 23 & 14.6 & 112 & 13.1 & 0.61 \\
\hline \multicolumn{2}{|l|}{ Depression } & 44 & 31.4 & 166 & 20.1 & 0.003 \\
\hline \multicolumn{2}{|l|}{ Cancer } & 20 & 12.7 & 45 & 5.2 & 0.0005 \\
\hline \multirow[t]{3}{*}{ Physical activity ${ }^{\mathrm{c}}$} & Hardly any physical activity & 62 & 39.5 & 161 & 18.8 & \multirow[t]{3}{*}{$<0.000$} \\
\hline & Light exercise & 58 & 37.0 & 370 & 43.3 & \\
\hline & Moderate to intense exercise & 37 & 23.6 & 324 & 37.9 & \\
\hline Angiotensin use & & 7 & 4.4 & 44 & 5.1 & 0.71 \\
\hline ACE inhibitor us & & 11 & 6.7 & 19 & 2.2 & 0.001 \\
\hline $\begin{array}{l}{ }^{\mathrm{a}} \text { Median }(25 \mathrm{t} \\
\text { percent of partici } \\
\text { variables with mu } \\
\mathrm{b} \text { esRAGE }=\mathrm{E} \\
\text { cation end produ }\end{array}$ & $\begin{array}{l}\text { h, } 75 \text { th percentile) for continuous } \\
\text { pants with specific characteristic a } \\
\text { altiple categories, row percentages a } \\
\text { ndogenous secretory receptor for ac } \\
\text { cts. }\end{array}$ & $\begin{array}{l}\text { ables or } \\
\text { ted. For } \\
\text { own. } \\
\text { ced gly- }\end{array}$ & $\begin{array}{l}{ }^{\mathrm{c}} \text { Hardly any } \mathrm{p} \\
\text { ing; Light exercis } \\
\text { tense exercise }= \\
\text { week; moderate e } \\
\text { per week; walk 5- }\end{array}$ & $\begin{array}{l}\text { al acti } \\
\text { ght ex } \\
\text { cate e } \\
\text { e }>3 \\
\text { day, } 5\end{array}$ & $\begin{array}{l}=\text { Mostly sitting ar } \\
\text { se } 2-4 \mathrm{~h} / \text { week; } \mathrm{M} \\
\text { se } 1-2 \mathrm{~h} \text { or light } \\
\text { ek; intense exercis } \\
\text { ys/week, } 5+\text { years. }\end{array}$ & $\begin{array}{l}\text { ome walk- } \\
\text { rate to in- } \\
\text { cise }>4 \mathrm{~h} / \\
\text { hany times }\end{array}$ \\
\hline
\end{tabular}

CML and esRAGE was placed in both multivariable logistic and Cox proportional hazards models to determine the modification effects of CML on the outcome. The statistical program used was SAS Version 9.1 (SAS Institute, Inc., Cary, N.C., USA). The level of significance used in this study was $\mathrm{p}<0.05$.

esRAGE and Renal Disease in the Elderly

\section{Results}

The demographic and health characteristics of the 1,016 men and women $\geq 65$ years old included in the study are shown in table 1 according to CKD diagnosis. 
Table 2. Multivariate logistic regression models of the cross-sectional relationship of plasma esRAGE at enrollment with CKD in the InCHIANTI study

\begin{tabular}{|c|c|c|c|c|c|c|c|c|c|}
\hline & \multicolumn{3}{|c|}{$\begin{array}{l}\text { Model adjusted for age, } \\
\text { gender, CML }\end{array}$} & \multicolumn{3}{|c|}{$\begin{array}{l}\text { Model adjusted for age, gender, } \\
\text { CML, education, smoking, } \\
\text { MMSE, and physical activity }\end{array}$} & \multicolumn{3}{|c|}{$\begin{array}{l}\text { Model adjusted for age, gender, } \\
\text { CML, log IL-6, education, smoking, } \\
\text { MMSE, physical activity, ACE } \\
\text { inhibitors use, and chronic diseases }\end{array}$} \\
\hline & OR & $95 \% \mathrm{CI}$ & $\mathrm{p}$ & OR & $95 \% \mathrm{CI}$ & $\mathrm{p}$ & OR & $95 \% \mathrm{CI}$ & $\mathrm{p}$ \\
\hline \multicolumn{10}{|l|}{ Plasma esRAGE ${ }^{a}, n g / m l$} \\
\hline Subjects without diabetes $(\mathrm{n}=881)$ & 1.33 & $(1.1,1.6)$ & 0.002 & 1.31 & $(1.1,1.6)$ & 0.004 & 1.42 & $(1.2,1.7)$ & 0.0006 \\
\hline
\end{tabular}

a Odds ratio (OR) expressed per $1 \mathrm{SD}$ of plasma esRAGE $(1 \mathrm{SD}=0.24 \mathrm{ng} / \mathrm{ml})$.

${ }^{\mathrm{b}}$ Chronic diseases were congestive heart failure, stroke, depression, and cancer.

Table 3. Multivariate Cox proportional hazards models of plasma esRAGE at enrollment and incident CKD over 6 years of follow-up in the InCHIANTI study

\begin{tabular}{|c|c|c|c|c|c|c|c|c|c|}
\hline & \multicolumn{3}{|c|}{$\begin{array}{l}\text { Model adjusted for age, } \\
\text { gender, CML }\end{array}$} & \multicolumn{3}{|c|}{$\begin{array}{l}\text { Model adjusted for age, gender, } \\
\text { CML, education, smoking, } \\
\text { MMSE, and physical activity }\end{array}$} & \multicolumn{3}{|c|}{$\begin{array}{l}\text { Model adjusted for age, gender, } \\
\text { CML, log IL-6, education, smoking, } \\
\text { MMSE, physical activity, ACE } \\
\text { inhibitors use, and chronic diseases }\end{array}$} \\
\hline & HR & $95 \% \mathrm{CI}$ & $\mathrm{p}$ & HR & $95 \%$ CI & $\mathrm{p}$ & HR & $95 \%$ CI & $\mathrm{p}$ \\
\hline \multicolumn{10}{|l|}{ Plasma esRAGE ${ }^{a}, n g / m l$} \\
\hline All subjects $(\mathrm{n}=858)$ & 1.36 & $(1.1,1.7)$ & 0.006 & 1.42 & $(1.1,1.8)$ & 0.002 & 1.37 & $(1.1,1.7)$ & 0.008 \\
\hline Subjects without diabetes $(\mathrm{n}=746)$ & 1.34 & $(1.1,1.7)$ & 0.02 & 1.40 & $(1.1,1.8)$ & 0.007 & 1.36 & $(1.1,1.8)$ & 0.02 \\
\hline
\end{tabular}

${ }^{a}$ Hazard ratio (HR) expressed per 1 SD of plasma esRAGE $(1 \mathrm{SD}=0.24 \mathrm{ng} / \mathrm{ml})$.

${ }^{\mathrm{b}}$ Chronic diseases were congestive heart failure, stroke, depression, and cancer.

Overall, mean (SD) plasma esRAGE was 0.45 (0.24) ng/ $\mathrm{ml}$ and 158 (15.5\%) participants had CKD. Participants with CKD were more likely to be older, male, non-smokers, taking ACE inhibitors, to have higher levels of log IL6 , and to have a lower level of education, lower physical activity, cognitive impairment, congestive heart failure, stroke, depression, and cancer. There were no significant differences in BMI, levels of log CRP or prevalence of hypertension, angina, peripheral artery disease, or diabetes mellitus between those with and without CKD. There was a low but significant positive correlation between plasma CML and esRAGE in the present study (Spearman correlation $0.082, \mathrm{p}<0.01$ ).

The relationship between plasma esRAGE and prevalent CKD at enrollment was examined in separate multivariable logistic regression models, adjusting for potential confounders as shown in table 2 . High concentrations of plasma esRAGE were associated with increased odds of CKD after adjusting for age, gender, CML, log IL-6, education, smoking, MMSE, physical activity, ACE inhibitor use, and chronic diseases. After excluding all patients with diabetes in the same model, higher concentrations of plasma esRAGE were associated with increased odds of CKD. In the present study, there were no significant modification effects of plasma CML on plasma esRAGE with CKD at enrollment $(\mathrm{p}=0.30)$.

Of 858 patients who did not have CKD at enrollment, 87 (10.1\%) developed CKD over 6 years of follow-up. Higher concentrations of plasma esRAGE predicted incident CKD in multivariable Cox proportional hazards models, adjusting for age, gender, CML, log IL-6, education, smoking, MMSE, physical activity, ACE inhibitor use, and chronic diseases as shown in table 3. High concentrations of plasma esRAGE were associated with incident CKD af- 
ter excluding patients with diabetes in multivariable Cox proportional hazards models, adjusting for the same covariates as above. There were no significant modification effects of plasma CML on plasma esRAGE with incident CKD over 6 years of follow-up $(\mathrm{p}=0.68)$.

\section{Discussion}

The present study suggests that older men and women with elevated plasma esRAGE are at a greater risk of developing CKD. Previous studies have primarily focused on the relationship between esRAGE and renal function in patients with specific diseases such as diabetes, atherosclerosis, and ESRD $[6,12,17]$. To our knowledge, this is the first study to describe the relationship between esRAGE and CKD in a population-based sample of older men and women. Another important observation of this study is that elevated levels of plasma esRAGE were predictive of CKD in men and women without diabetes. The association between esRAGE and CKD was even stronger after exclusion of participants with diabetes. The present study is consistent with previous studies that have shown an association of elevated sRAGE and esRAGE with decreased renal function $[10,11,14,18]$. These findings are consistent with the idea that esRAGE could potentially serve as a biomarker to predict and monitor several inflammatory and chronic disease states [19].

Consistent with previous reports, in the present study, plasma CML was associated with kidney disease [20]. There was a low but significant positive correlation between plasma CML and esRAGE in the present study. In the circulation, esRAGE comprises about one third of total sRAGE. A previous study reported a positive association between circulating AGEs and sRAGE [21]. In the present study, no interaction was found between CML and esRAGE. The interaction of AGE with RAGE has previously been shown to upregulate the expression of RAGE [22].

High levels of circulating RAGE have been hypothesized to have a decoy function in binding with AGEs and preventing activation of the AGE-RAGE pathway. Thus, according to this hypothesis, low plasma esRAGE would be associated with worse disease. In young adults with type 1 diabetes, low serum esRAGE was associated with microalbuminuria [23]. These results contrast with the present study, which shows that elevated esRAGE is associated with higher risk of CKD and other studies that show increased esRAGE is associated with compromised renal function [11].
Plasma esRAGE remained a strong predictor of CKD even after adjusting for an important inflammatory cytokine, IL-6. AGE-RAGE binding is known to upregulate many inflammatory cytokines such as TNF- $\alpha$, IL- 6 , and CRP via the NF- $\kappa B$ pathway [3]. In the present study, elevated levels of IL- 6 were significantly correlated to CKD. IL- 6 plays a central role in inflammation by inducing the production of many acute phase proteins, including CRP. However, in the present study, no significant relationship was found between CRP and CKD.

The study has some limitations that include the use of the MDRD study equation, which has not yet been validated in adults $>70$ years of age. The serum creatinine measurements in the present study were not standardized using the isotope dilution mass spectrometry-traceable MDRD study equation [24]. Participants were seen only every 3 years and some of the participants who died during follow-up intervals may have developed CKD prior to death. Total sRAGE was not measured in the present study, and esRAGE comprises about one third of the total sRAGE in the circulation. Previous studies have shown that the ligand to RAGE, S100A12, is more strongly associated with cardiovascular disease in patients with decreased renal function than RAGE, even after adjusting for inflammatory markers such as CRP and IL-6 $[18,25]$. Our study does not include measurements of S100A12 and therefore no insight into the relationship between S100A12 and CKD can be gained. Further studies are needed to determine the exact relationship between S100A12, sRAGE, and CKD.

In conclusion, elevated plasma esRAGE was independently associated with CKD and was an independent predictor of CKD development in older community-dwelling men and women with and without diabetes.

\section{Acknowledgements}

This work was supported by National Institute on Aging Grants R01 AG027012, R01 AG029148, R01 HL094507, the Italian Ministry of Health (ICS110.1/RF97.71), NIA contracts $263 \mathrm{MD}$ 9164, 263 MD 821336, N.1-AG-1-1, N.1-AG-1-2111, and N01AG-5-0002, and the Intramural Research Program, National Institute on Aging, National Institutes of Health.

\section{Disclosure Statement}

The authors have no conflicts of interest to disclose. 


\section{References}

$\checkmark 1$ Lederer E, Ouseph R: Chronic kidney disease. Am J Kidney Dis 2007;49:162-171.

-2 Vlassara H, Torreggiani M, Post J, Zheng F, Uribarri J, Striker G: Role of oxidants/inflammation in declining renal function in chronic kidney disease and normal aging. Kidney Int 2009;114(suppl):S3-S11.

-3 Vlassara H, Striker G: Glycotoxins in the diet promote diabetes and diabetic complications. Curr Diab Rep 2007;7:235-241.

-4 Basta G, Schmidt AM, De Caterina R: Advanced glycation end products and vascular inflammation: implications for accelerated atherosclerosis in diabetes. Cardiovasc Res 2004;63:582-592.

-5 Bohlender JM, Franke S, Stein G, Wolf G: Advanced glycation end products and the kidney. Am J Physiol Renal Physiol 2005; 289:F645-F659.

6 Basta G: Receptor for advanced glycation end products and atherosclerosis: from basic mechanisms to clinical implications. Atherosclerosis 2008;196:9-21.

-7 Stern D, Yan SD, Yan SF, Schmidt AM: Receptor for advanced glycation end products: a multiligand receptor magnifying cells stress in diverse pathologic settings. Adv Drug Deliv Rev 2002;54:1615-1625.

$\checkmark 8$ Yonekura H, Yamamoto Y, Sakurai S, Petrova RG, Abedin MJ, Li H, Yasui K, Takeuchi M, Makita Z, Takasawa S, Okamoto H, Watanabe T, Yamamoto H: Novel splice variants of the receptor for advanced glycation end-products expressed in human vascular endothelial cells and pericytes, and their putative roles in diabetes-induced vascular injury. Biochem J 2003;370:1097-1109.

-9 Raucci A, Cugusi S, Antonelli A, Barabino SM, Monti L, Bierhaus A, Reiss K, Saftig P, Bianchi ME: A soluble form of the receptor for advanced glycation endproducts (RAGE) is produced by proteolytic cleavage of the membrane-bound form by the sheddase a disintegrin and metalloprotease 10 (ADAM10). FASEB J 2008;10:3716-3727.
10 Nin JW, Ferreira I, Schalkwijk CG, Prins $\mathrm{MH}$, Chaturvedi N, Fuller JH, Stehouwer CD, EURODIAB Prospective Complications Study Group: Levels of soluble receptor for AGE are cross-sectionally associated with cardiovascular disease in type 1 diabetes, and this association is partially mediated by endothelial and renal dysfunction and by low-grade inflammation: the EURODIAB Prospective Complications Study. Diabetologia 2009;52:705-714.

11 Gohda T, Tanimoto M, Moon JY, Gotoh H, Aoki T, Matsumoto M, Shibata T, Ohsawa I, Funabiki K, Tomino Y: Increased serum endogenous secretory receptor for advanced glycation end-product (esRAGE) levels in type 2 diabetic patients with decreased renal function. Diabetes Res Clin Pract 2008;81: 196-201.

12 Kalousová M, Hodková M, Kazderová M, Fialová J, Tesar V, Dusilová-Sulková S, Zima T: Soluble receptor for advanced glycation end products in patients with decreased renal function. Am J Kidney Dis 2006;47:406411.

13 Koyama H, Shoji T, Fukumoto S, Shinohara K, Shoji T, Emoto M, Mori K, Tahara $\mathrm{H}$, Ishimura E, Kakiya R, Tabata T, Yamamoto $\mathrm{H}$, Nishizawa Y: Low circulating endogenous secretory receptor for AGEs predicts cardiovascular mortality in patients with end-stage renal disease. Arterioscler Thromb Vasc Biol 2007;27:147-153.

14 Semba RD, Ferrucci L, Fink JC, Sun K, Beck J, Dalal M, Guralnik JM, Fried LP: Advanced glycation end products and their circulating receptors and level of kidney function in older community-dwelling women. Am J Kidney Dis 2009;53:51-58.

15 Levey AS, Bosch JP, Lewis JB, Greene T, Rogers N, Roth D: A more accurate method to estimate glomerular filtration rate from serum creatinine: a new prediction equation. Modification of Diet in Renal Disease Study Group. Ann Intern Med 1999;130:461-470.

-16 Zhang X, Frischmann M, Kientsch-Engel R, Steinmann K, Stopper H, Niwa T, Pischetsrieder M: Two immunochemical assays to measure advanced glycation end-products in serum from dialysis patients. Clin Chem Lab Med 2005;43:503-511.

17 Nishizawa Y, Koyama H: Endogenous secretory receptor for advanced glycation endproducts and cardiovascular disease in endstage renal disease. J Ren Nutr 2008;8:76-82.
18 Nakashima A, Carrero JJ, Qureshi AR, Miyamoto T, Anderstam B, Bárány P, Heimbürger O, Stenvinkel P, Lindholm B: Effect of circulating soluble receptor for advanced glycation end products (sRAGE) and the proinflammatory RAGE ligand (ES-RAGE, S100A12) on mortality in hemodialysis patients. Clin J Am Soc Nephrol 2010;5:22132219.

19 Yan SF, Ramasamy R, Schmidt AM: Soluble RAGE: Therapy and biomarker in unraveling the RAGE axis in chronic disease and aging. Biochem Pharmacol 2010;15;79:13791386

20 Mostafa AA, Randell EW, Vasdev SC, Gill VD, Han Y, Gadag V, Raouf AA, El Said H: Plasma protein advanced glycation end products, carboxymethyl cysteine, and carboxyethyl cysteine, are elevated and related to nephropathy in patients with diabetes. Mol Cell Biochem 2007;302:35-42.

-21 Yamagishi S, Adachi H, Nakamura K, Matsui T, Jinnouchi Y, Takenaka K, Takeuchi M, Enomoto M, Furuki K, Hino A, Shigeto Y, Imaizumi T: Positive association between serum levels of advanced glycation end products and the soluble form of receptor for advanced glycation end products in nondiabetic subjects. Metabolism 2006;55:1227-1231.

22 Santilli F, Vazzana N, Bucciarelli LG, Davì G: Soluble forms of RAGE in human diseases: clinical and therapeutic implications. Curr Med Chem 2009;16:940-952.

23 Marchovecchio ML, Gianninit C, Dalton RN, Widmer B, Chiarelli F, Dunger DB: Reduced endogenous secretory receptor for advanced glycation end products (esRAGE) in young people with type 1 diabetes developing microalbuminuria. Diabetic Med 2009; 26:815-819.

24 Levey AS, Coresh J, Greene T, Marsh J, Stevens LA, Kusek JW, Van Lente F, Chronic Kidney Disease Epidemiology Collaboration: Chronic Kidney Disease Epidemiology Collaboration: Expressing the Modification of Diet in Renal Disease Study equation for estimating glomerular filtration rate with standardized serum creatinine values. Clin Chem 2007;53:766-772.

25 Mori Y, Kosaki A, Kishimoto N, Kimura T, Iida K, Fukui M, Nakajima F, Nagahara M, Urakami M, Iwasaka T, Matsubara H: Increased plasma S100A12 (EN-RAGE) levels in hemodialysis patients with atherosclerosis. Am J Nephrol 2009;29:18-24. 